\title{
ADSORPTION OF HCOOH ON Rh(111) AND ITS REACTION WITH PREADSORBED OXYGEN
}

\author{
Frigyes SOLYMOSI, János KISS and Imre KOVÁCS \\ Reaction Kinetics Research Group of the Hungarian Academy of Sciences and Institute of Solid State \\ and Radiochemistry, University of Szeged, P.O. Box 105, H-6701 Szeged, Hungary
}

Received 25 March 1987; accepted for publication 30 July 1987

\begin{abstract}
The interaction of formic acid with clean and oxygen-dosed $\mathrm{Rh}(111)$ surfaces has been investigated by electron energy loss (in the electronic range), thermal desorption and photoelectron spectroscopy. Formic acid adsorbs readily on the $\mathrm{Rh}(111)$ surface at $100 \mathrm{~K}$ with a high sticking probability. Three adsorbed states have been distinguished: a condensed layer $\left(T_{\mathrm{p}}=170\right.$ $\mathrm{K})$, a chemisorbed layer $\left(T_{\mathrm{p}}=202 \mathrm{~K}\right)$ and the formation of formate species. The latter is stable up to $200 \mathrm{~K}$, but decomposes completely at $200-250 \mathrm{~K}$. The major products are: $\mathrm{H}_{2}\left(T_{\mathrm{p}}=323 \mathrm{~K}\right)$ and $\mathrm{CO}_{2}\left(T_{\mathrm{p}}=255-290 \mathrm{~K}\right)$, but $\mathrm{H}_{2} \mathrm{O}\left(T_{\mathrm{p}}=263 \mathrm{~K}\right)$ and $\mathrm{CO}\left(T_{\mathrm{p}}=530 \mathrm{~K}\right)$ are also formed. Preadsorbed oxygen exerted a readily observable influence on the interaction of $\mathrm{HCOOH}$ with the $\mathrm{Rh}(111)$ surface. It increased the extent of dissociation of $\mathrm{HCOOH}$ and extended the region of stability of surface formate by at least $80-100 \mathrm{~K}$. This was demonstrated by higher stability of photoemission peaks due to formate and by simultaneous production of $\mathrm{CO}_{2}$ and $\mathrm{H}_{2} \mathrm{O}$ with $T_{\mathrm{p}}=377-385 \mathrm{~K}$ at saturation oxygen coverage.
\end{abstract}

\section{Introduction}

It has emerged that adsorbed formate is one of the surface intermediates in various catalytic reactions on supported $R h$ catalysts. It has been detected by infrared spectroscopy in the water-gas shift reaction [1], in the synthesis and decomposition of $\mathrm{CH}_{3} \mathrm{OH}[2]$, and in the methanation of $\mathrm{CO}[3,4]$ and $\mathrm{CO}_{2}$ [5-7]. Strong bands due to adsorbed formate are also produced in the low-temperature surface interaction of $\mathrm{H}_{2}+\mathrm{CO}_{2}$ [8-10]. The situation is complicated by the fact that the formate species detected is mostly located not on the metal, but on the support. However, we recently showed that even the formate residing on the support can be transformed into $\mathrm{CH}_{4}$ by reaction with hydrogen activated on the Rh. Although this route was considered to be a minor one in the production of $\mathrm{CH}_{4}$, it was demonstrated that formate species bonded adjacent to the $\mathrm{Rh}$ cannot be regarded as a totally inactive surface species in the hydrogenation of $\mathrm{CO}$ and $\mathrm{CO}_{2}$ [11]. An important contribution to this field was provided by Deluzarche et al. [12-14], who developed a sensitive method of chemical trapping for the detection of surface formate.

0039-6028/87/\$03.50 @ Elsevier Science Publishers B.V.

(North-Holland Physics Publishing Division) 
They presented convincing evidence that the formate species is an important surface intermediate in $\mathrm{CH}_{3} \mathrm{OH}$ synthesis. More information on the role of the formate species in the reactions of carbon oxides with $\mathrm{H}_{2}$ on other catalysts can be found in an excellent review by Deluzarche et al. [14].

In order to clarify the role of the formate species in the above reactions, we need to know more about its surface behavior and reactions on the clean metals themselves. We earlier investigated the adsorption of $\mathrm{HCOOH}$ on polycrystalline Rh [15]. In the present work the interaction of $\mathrm{HCOOH}$ with an ordered surface structure of Rh, i.e. the (111) face is examined, in combination with a study of the effect of preadsorbed oxygen. In a following paper [16], we shall report on the effect of potassium additive on the adsorption and decomposition of $\mathrm{HCOOH}$ on the $\mathrm{Rh}(111)$ surface.

\section{Experimental}

Experiments were performed in a stainless steel UHV chamber equipped with several gas inlets, a four-grid retarding field analyser for Auger electron spectroscopy and for low-energy electron diffraction (LEED) and a quadrupole mass analyser for thermal desorption spectroscopy. The electron energy loss spectra (EELS in electronic range) were taken by means of cylindrical mirror analyzer. Changes in work function were obtained from the low energy cut off in the EEL spectra [17]. The beam energy was $70 \mathrm{eV}$, the beam intensity was restricted to $0.05 \mu \mathrm{A}$. The vacuum system was evacuated with ion pumps and a titanium getter pump.

UPS measurements were performed in an other UHV system. The photoelectrons were detected by an electrostatic hemispherical energy analyzer (Leybold-Hereaus LHS 10). The photon source (He I, He II) was pumped differentialy. The UPS spectra were taken with an instrumental resolution of $0.2 \mathrm{eV}$. All binding energies are referenced to the Fermi level of rhodium. The difference spectra were obtained by means of a Tracor TN 1710 multichannel analyzer. The spectra were stored by a microcomputer connected to the Tracor analyzer. The vacuum system was evacuated by a turbomolecular pump and a titanium getter.

The $\mathrm{Rh}$ crystal was cut from a single crystal. It was a product of Materials Research Corporation; the purity was $99.99 \%$. The sample was heated resistively and its temperature was measured by a chromel-alumel thermocouple spot-welded to the edge of crystal. For low-temperature measurements the Rh sample was cooled by a Ta foil spotwelded to the sample and connected to a liquid-nitrogen-cooled stainless tube. As the $\mathrm{Rh}$ sample has been used in a number of our previous studies, it was sufficient to clean the sample by argon ion bombardment $\left(600 \mathrm{eV}, 1 \times 10^{-6}\right.$ Torr Ar, $3 \mu \mathrm{A}$ for $\left.10-30 \mathrm{~min}\right)$, and annealing at $1270 \mathrm{~K}$ for some minutes. 
$\mathrm{HCOOH}$ was a product of Merck. It was purified in the manner reported earlier [15]. Extended vacuum evaporation removed $\mathrm{CH}_{3} \mathrm{OH}$ and $\mathrm{CH}_{3} \mathrm{COOH}$.

\section{Results}

\subsection{Clean $R h(111)$}

\subsubsection{Thermal desorption measurements}

Fig. 1 shows some characteristic desorption spectra of $\mathrm{HCOOH}$ as a function of $\mathrm{HCOOH}$ exposure at $100 \mathrm{~K}$. Low exposure produced only a single peak $(\beta)$ with a peak temperature, $T_{\mathrm{p}}=202 \mathrm{~K}$, which did not exhibit a dependence on the $\mathrm{HCOOH}$ exposure. Below $\sim 0.5 \mathrm{~L} \mathrm{HCOOH}$ exposure, no desorption of $\mathrm{HCOOH}$ was detected. Above a $\mathrm{HCOOH}$ exposure of $5 \mathrm{~L}$ another peak $(\alpha)$ developed, with a $T_{\mathrm{p}}$ of $170 \mathrm{~K}$, which slightly increased with coverage indicating a zero-order kinetics. While the $\beta$-state became saturated at about $6 \mathrm{~L}$, saturation was not reached for the $\alpha$-peak up to $30 \mathrm{~L}$ (fig. 1).

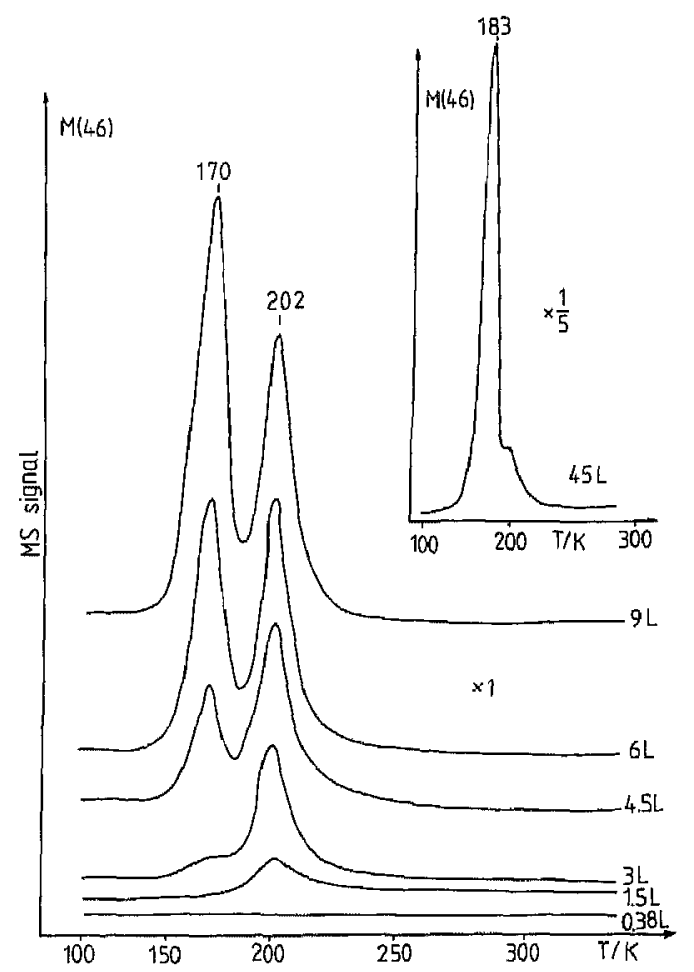

Fig. 1. Thermal desorption spectra of $\mathrm{HCOOH}$ following $\mathrm{HCOOH}$ adsorption on clean $\mathrm{Rh}(111)$ at $100 \mathrm{~K}$. 

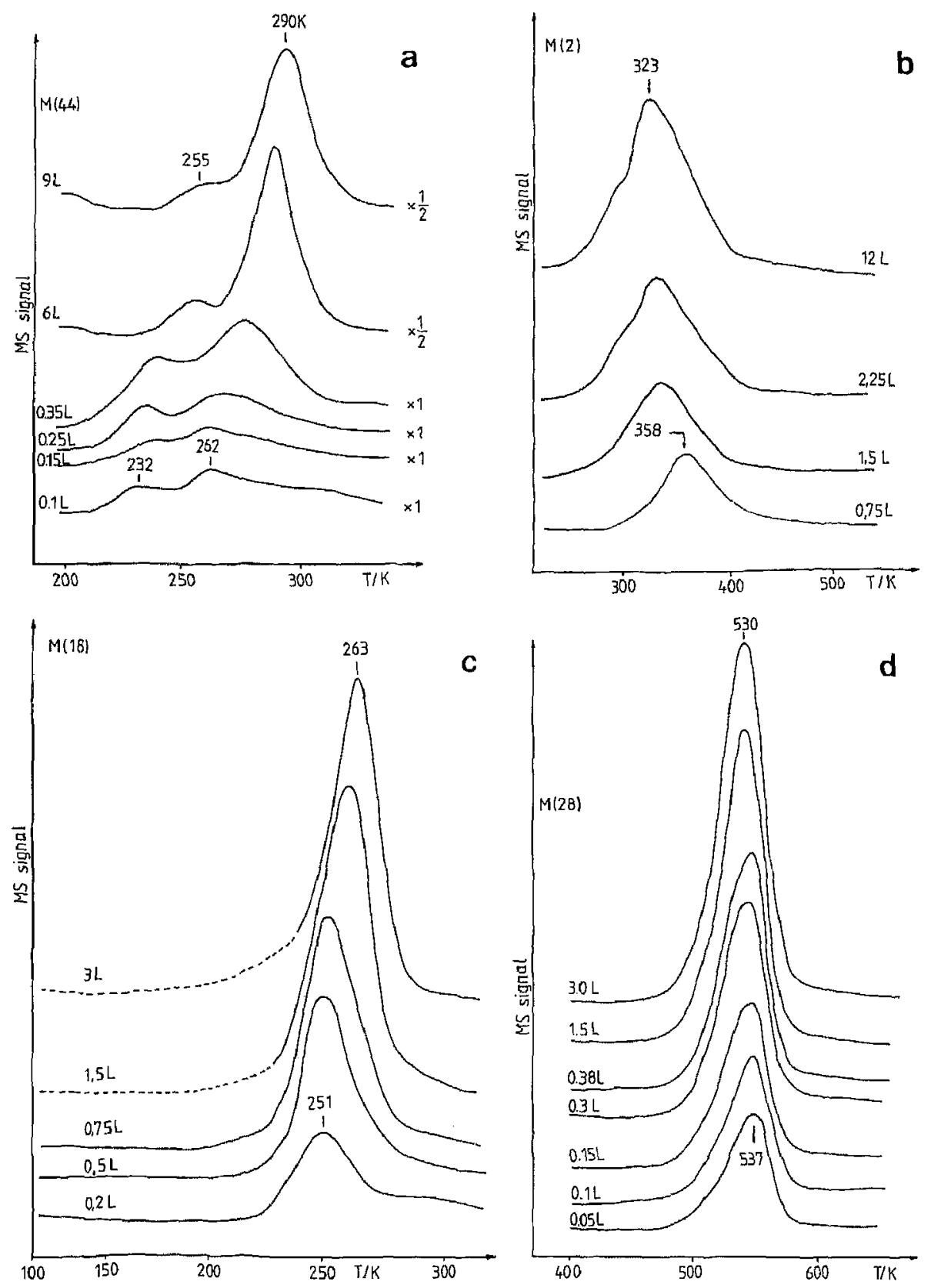

Fig. 2. Thermal desorption of $\mathrm{CO}_{2}$ (a), $\mathrm{H}_{2}$ (b), $\mathrm{H}_{2} \mathrm{O}$ (c) and $\mathrm{CO}$ (d) following $\mathrm{HCOOH}$ adsorption on clean $\mathrm{Rh}(111)$ at $100 \mathrm{~K}$. 
Quantitative analysis of the peak areas, taking into account the pumping rate and mass spectrometer sensitivity for $\mathrm{HCOOH}$, demonstrated that in the $\beta$-state the surface concentration was approximately $5.5 \times 10^{13} \mathrm{HCOOH}$ molecules $/ \mathrm{cm}^{2}$. As regards the accuracy of this value, we may recall the statement of Christmann and Demuth [18]: "Such absolute values are inherently uncertain $( \pm 50 \%)$ as the effective pumping speed and gauge calibration factors are not precisely defined".

Besides $\mathrm{HCOOH}$, the formation of $\mathrm{CO}_{2}, \mathrm{H}_{2}, \mathrm{H}_{2} \mathrm{O}$ and $\mathrm{CO}$ was observed at higher temperatures, suggesting that a more strongly adsorbed species remained on the surface and decomposed to these products at higher temperatures. Even at the lowest exposures $\mathrm{CO}_{2}$ desorbed in two peaks, with $T_{\mathrm{p}}=232$ $\mathrm{K}\left(\beta_{1}\right)$ and $262 \mathrm{~K}\left(\beta_{2}\right)$. With increase of the $\mathrm{HCOOH}$ exposure, the peak temperatures of both peaks shifted to higher values, $255 \mathrm{~K}\left(\beta_{1}\right)$ and $290 \mathrm{~K}$ $\left(\beta_{2}\right)$ (fig. 2a). An important feature is that the amount of $\mathrm{CO}_{2}$ desorbed in the $\beta_{2}$ state increased considerably with rise of the $\mathrm{HCOOH}$ exposure: the corresponding increase was much less for the $\beta_{1}$ state. In contrast to the behavior of $\mathrm{CO}_{2}$, the $\mathrm{H}_{2}$ desorption maximum shifted from 358 to $323 \mathrm{~K}$ with increasing $\mathrm{HCOOH}$ exposure. At higher exposures, a shoulder developed at $293 \mathrm{~K}$ (fig. 2b). A small amount of $\mathrm{H}_{2} \mathrm{O}$ was also detected among the desorption products: a desorption maximum was located at $251-263 \mathrm{~K}$ (fig. 2c). The desorption of $\mathrm{CO}$ occurred at highest temperatures, with a slight shift in its $T_{\mathrm{p}}$ from 537 to $530 \mathrm{~K}$ (fig. $2 \mathrm{~d}$ ).

In fig. 3 the amounts of the desorption products are plotted as a function of the $\mathrm{HCOOH}$ exposure. It appears that saturation for $\mathrm{H}_{2}$ and $\mathrm{CO}_{2}$ is attained at about $10-12 \mathrm{~L}$, for $\mathrm{H}_{2} \mathrm{O}$ and $\mathrm{CO}$ at lower exposure at $2-3 \mathrm{~L}$. The ratio $\mathrm{H}_{2} / \mathrm{CO}_{2}$ is approximately 1.0 at all coverages. Whereas the ratio $\mathrm{CO}_{2} / \mathrm{CO}$ is below 1 at the lowest $\mathrm{HCOOH}$ exposure, it increases to about 4 at saturation, indicating a change in the stoichiometry of surface decomposition. Taking into account the sum of $\mathrm{CO}$ and $\mathrm{CO}_{2}$ at saturation and assuming that they are formed in the decomposition of adsorbed formate species (see later), we find that the concentration of the strongly adsorbed formate species is $6.3 \times 10^{14}$ $\mathrm{HCOO}$ molecules $/ \mathrm{cm}^{2}$.

The initial sticking coefficient $\left(S_{0}\right)$ of $\mathrm{HCOOH}$ adsorption, calculated from the plot of the total amount of chemisorbed $\mathrm{HCOOH}$ against exposure, was found to be -1 .

\subsubsection{EELS measurements}

The characteristic of the EEL spectrum of the Rh(111) sample agreed well with those established previously for a clean $\mathrm{Rh}$ surface, which have been discussed in detail $[19,20]$. The adsorption of $\mathrm{HCOOH}$ on a clean $\mathrm{Rh}(111)$ surface produced a new loss at $11.3 \mathrm{eV}$ at $100 \mathrm{~K}$ and at low exposure $(0.3 \mathrm{~L})$. Its intensity increased with the $\mathrm{HCOOH}$ exposure, and from about $2 \mathrm{~L}$ new loss features appeared at 14.8 and $7.9 \mathrm{eV}$. 

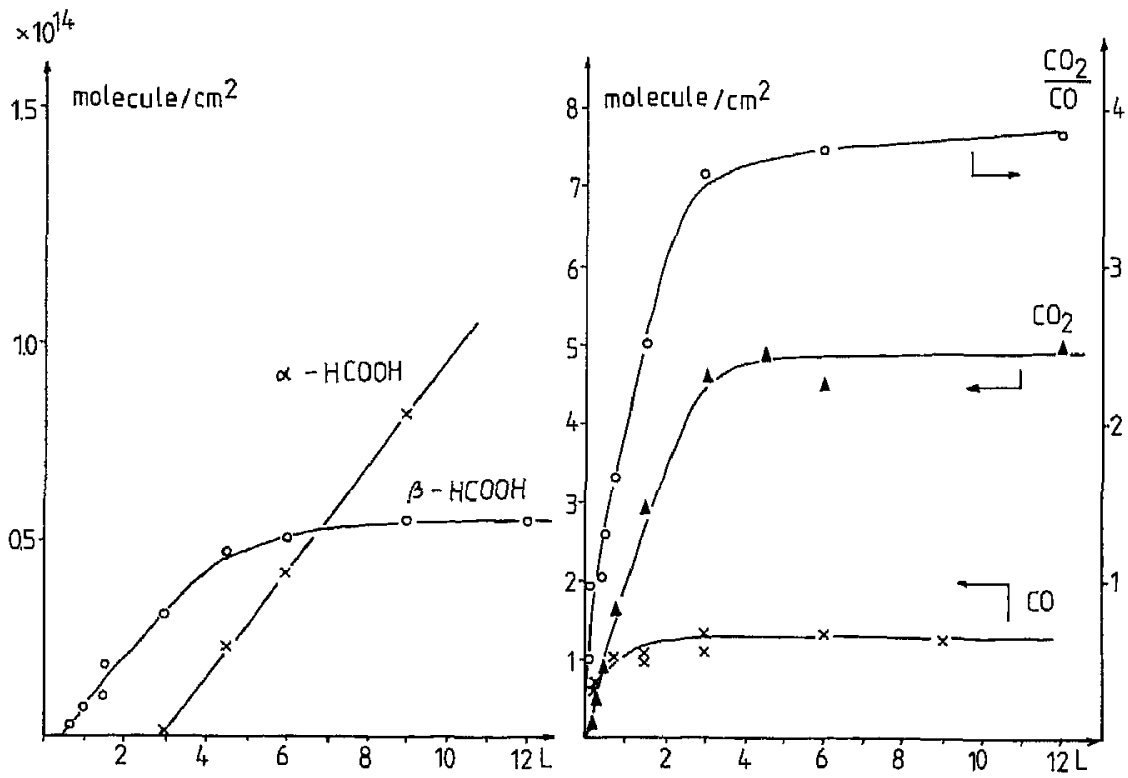

Fig. 3. The amount of desorbed products and their relations as a function of HCOOH exposure at $100 \mathrm{~K}$.

When the sample was heated to higher temperatures, the intensity of the 7.9 $\mathrm{eV}$ loss decreased rapidly and it disappeared at around $186 \mathrm{~K}$. The 11.3 and $14.8 \mathrm{eV}$ losses attenuated significantly up to $160 \mathrm{~K}$, but only slightly above this temperature (fig. 4). These losses were clearly detectable even at $228 \mathrm{~K}$. Above this temperature, another loss feature developed at $13.1 \mathrm{eV}$ from the rather broad peak. Its intensity increased up to $340 \mathrm{~K}$, but then decreased. It disappeared at slightly above $500 \mathrm{~K}$.

When the $\mathrm{Rh}(111)$ surface was exposed to $\mathrm{HCOOH}$ at $300 \mathrm{~K}$, only one loss appeared, at $13.2 \mathrm{eV}$.

\subsubsection{UPS studies}

Fig. 5A shows the He II photoelectron spectra of $\mathrm{Rh}(111)$ as a function of the $\mathrm{HCOOH}$ exposure at $100 \mathrm{~K}$. The adsorption of $\mathrm{HCOOH}$ at low exposure $(0.3 \mathrm{~L})$ produced an emission peak at $5.3 \mathrm{eV}$ and a weak broad feature between 8 and $12 \mathrm{eV}$. At higher exposure, peaks were observed at 6.2, 8.9, $10.5,11.9$ and $16.2 \mathrm{eV}$. The positions of these peaks correspond to the formation of chemisorbed $\mathrm{HCOOH}$. With the increase of the $\mathrm{HCOOH}$ exposure, the locations of these peaks shifted to higher energy. The shift for the low energy peak was most pronounced. At the same time, a drastic suppression in the intensity of the d-band of $\mathrm{Rh}$ also occurred. When the adsorbed 


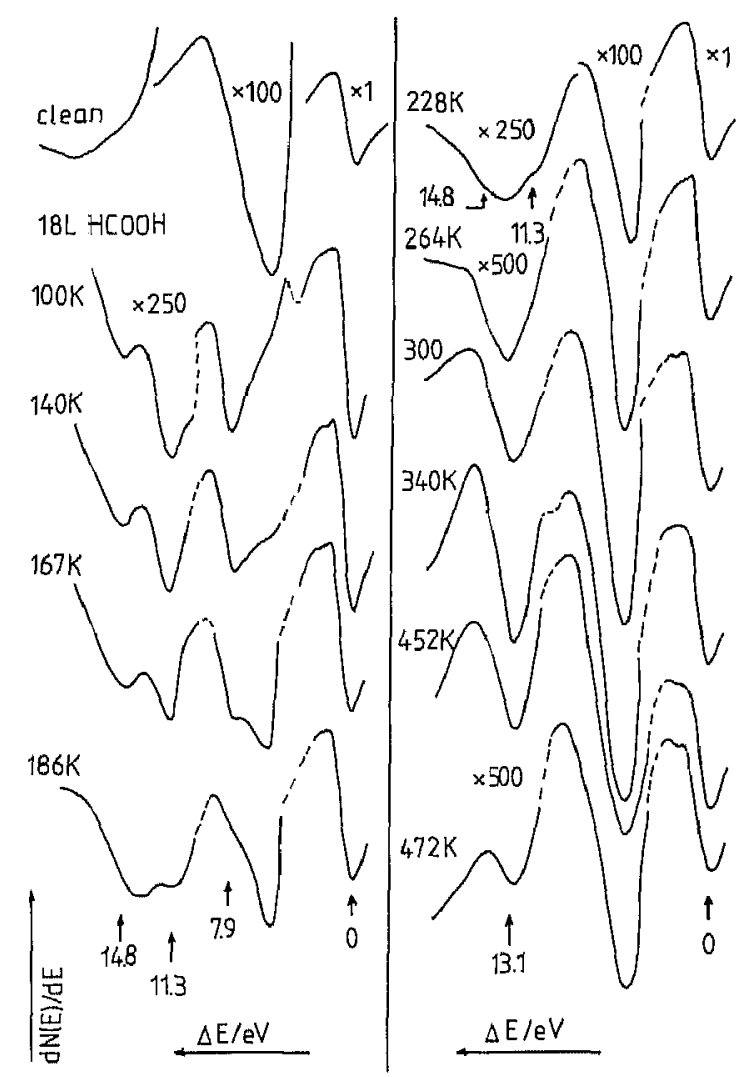

Fig. 4. Electron energy loss spectra following $\mathrm{HCOOH}$ atsorption on clean $\mathrm{Rh}(111)$ at $100 \mathrm{~K}$ and after gradually heating the saturated layer to different temperatures. Heating rate was $18 \mathrm{~K} \mathrm{~s}^{-I}$. The heating time at a given temperature was $2 \mathrm{~s}$.

layer was gradually heated to higher temperature, first the $16.2 \mathrm{eV}$ peak was eliminated at $151 \mathrm{~K}$, and the peak initially centred at $6.2 \mathrm{eV}$ shifted to lower binding energy, to $5.3 \mathrm{eV}$ (fig. 5B). A new photoemission peak at $13.2 \mathrm{eV}$,

Table 1

Binding energy data on the interaction of clean and oxygen-dosed Rh(111) with HCOOH

\begin{tabular}{lll}
\hline & $T_{\mathrm{a}}(\mathrm{K})$ & $E_{\mathrm{F}}(\mathrm{eV})$ \\
\hline Clean $\mathrm{Rh}(111)$ & 100 & $6.2,8.9,10.5,11.9,16.2$ \\
& $151-249$ & $5.3,8.6,10.2,13.2$ \\
& $267-522$ & $8.1,11.2$ \\
Oxygen-dosed & 100 & $6.0,8.1,9.1,10.9,15.1$ \\
Rh(111) & $215-350$ & $5.0,7.8,9.2,13.1$ \\
\hline
\end{tabular}



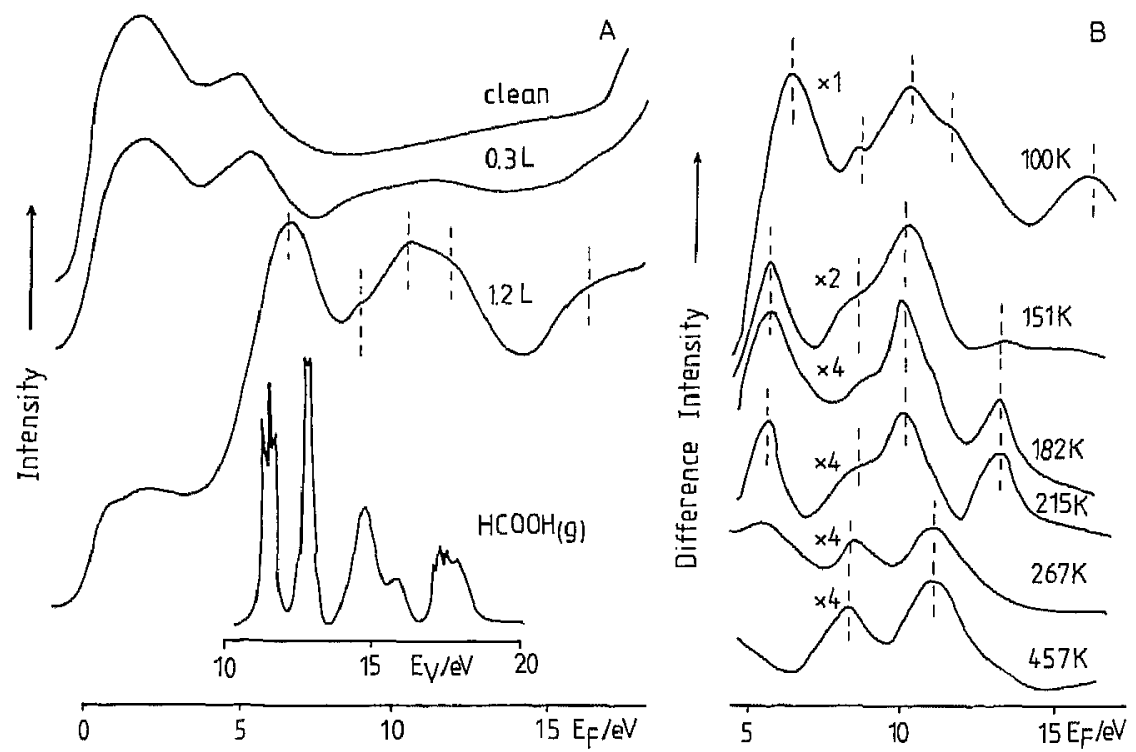

Fig. 5. He II photoelectron spectra of clean $\mathrm{Rh}(111)$ as a function of $\mathrm{HCOOH}$ exposure at $100 \mathrm{~K}$ (A) and after gradually heating the saturated layer to different temperatures (B). Spectrum of gaseous $\mathrm{HCOOH}$ is also shown [28].
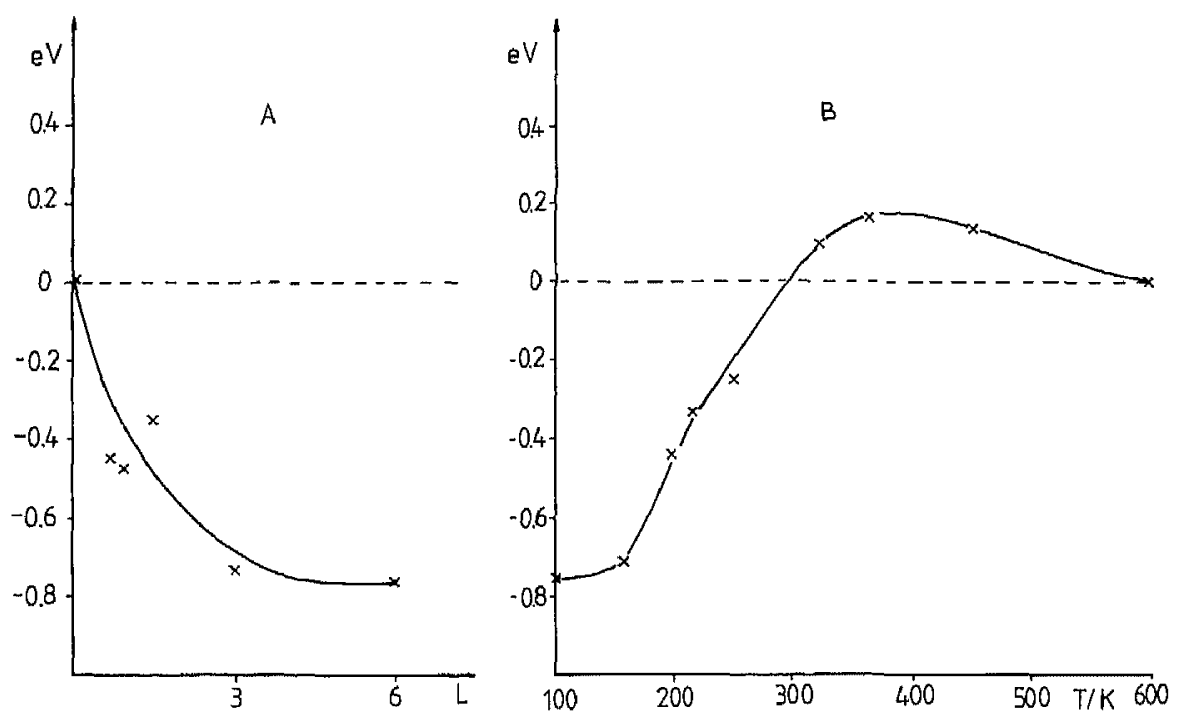

Fig. 6. Changes in the work function of clean $\mathrm{Rh}(111)$ as a function of $\mathrm{HCOOH}$ exposure at 100 $\mathrm{K}$ (A) and after gradually heating the saturated layer to different temperatures (B). 
indicative of the formation of formate anion (see later), was also clearly detected above $151 \mathrm{~K}$. All photoemission peaks, except the $13.2 \mathrm{eV}$ peak, attenuated at $151-200 \mathrm{~K}$. The intensity of the $13.2 \mathrm{eV}$ peak started to decrease only above $215 \mathrm{~K}$. This peak was completely eliminated around $249 \mathrm{~K}$. Other new photoemission peaks at 8.1 and $11.2 \mathrm{eV}$ (tentatively attributed to the adsorbed $\mathrm{CO}$ formed in the decomposition of formate species) were detectable from $267 \mathrm{~K}$. Their intensity increased from $267 \mathrm{~K}$ up to about $286 \mathrm{~K}$, and they started to attenuate above $457 \mathrm{~K}$. The spectrum characteristic of clean $\mathrm{Rh}$ was restored at about $522 \mathrm{~K}$. The observed photoemission peaks are listed in table 1.

\subsubsection{Work function measurements}

The exposure of a clean $\mathrm{Rh}(111)$ surface to $\mathrm{HCOOH}$ at $100 \mathrm{~K}$ decreased the work function of Rh by $0.75 \mathrm{eV}$ at the saturation of the $\beta$-state (fig. 6). When the HCOOH-saturated $(\beta)$ surface was heated, the work function gradually increased; it reached the value for a clean surface at around $300 \mathrm{~K}$. It increased further up to about $360 \mathrm{~K}$, but then decreased to reach the preadsorption $\mathrm{HCOOH}$ value by $550 \mathrm{~K}$.

\subsubsection{LEED studies}

Finally an attempt was made to determine long-range ordered structures on $\mathrm{Rh}(111)$ covered with adsorbed HCOOH. The clean Rh(111) surface exhibited a sharp $(1 \times 1)$ pattern. Exposures of $\mathrm{HCOOH}$ produced no new LEED patterns at $100 \mathrm{~K}$; a considerable increase in the background intensity was observed. Annealing to $170-180 \mathrm{~K}$ to remove the weakly bonded $\mathrm{HCOOH}$ did not give rise to a different picture.

\subsection{Oxygen-dosed surface}

\subsubsection{Thermal desorption measurements}

The concentration of adsorbed oxygen was calculated from the relative $O$ Auger signal $R_{0}\left(R_{0}=h_{\mathrm{O}_{512}} / h_{\mathrm{Rh}_{312}}\right)$, taking into account that at saturation the oxygen concentration is $8 \times 10^{14}$ oxygen atoms $/ \mathrm{cm}^{2}$, which corresponds to $\theta_{\mathrm{o}}=0.5[21]$.

Fig. 7 shows some thermal desorption spectra as a function of oxygen coverage. Preadsorbed oxygen exerted very little influence on the desorption of condensed and chemisorbed $\mathrm{HCOOH}$. The peak temperatures were hardly altered and the amounts of desorbed $\mathrm{HCOOH}$ in the $\alpha$ - and $\beta$-states differed only slightly.

A more dramatic effect was observed in the formation of the decomposition products. At $\theta_{\mathrm{O}}=0.08$ a shoulder appeared on the high-temperature side of the TD curve of $\mathrm{CO}_{2}$ which was transformed into a new high-temperature peak. Its $T_{\mathrm{p}}$ increased from $313 \mathrm{~K}$ at $\theta_{\mathrm{O}}=0.08$ to $385 \mathrm{~K}$ at $\theta_{\mathrm{O}}=0.5$. At the 

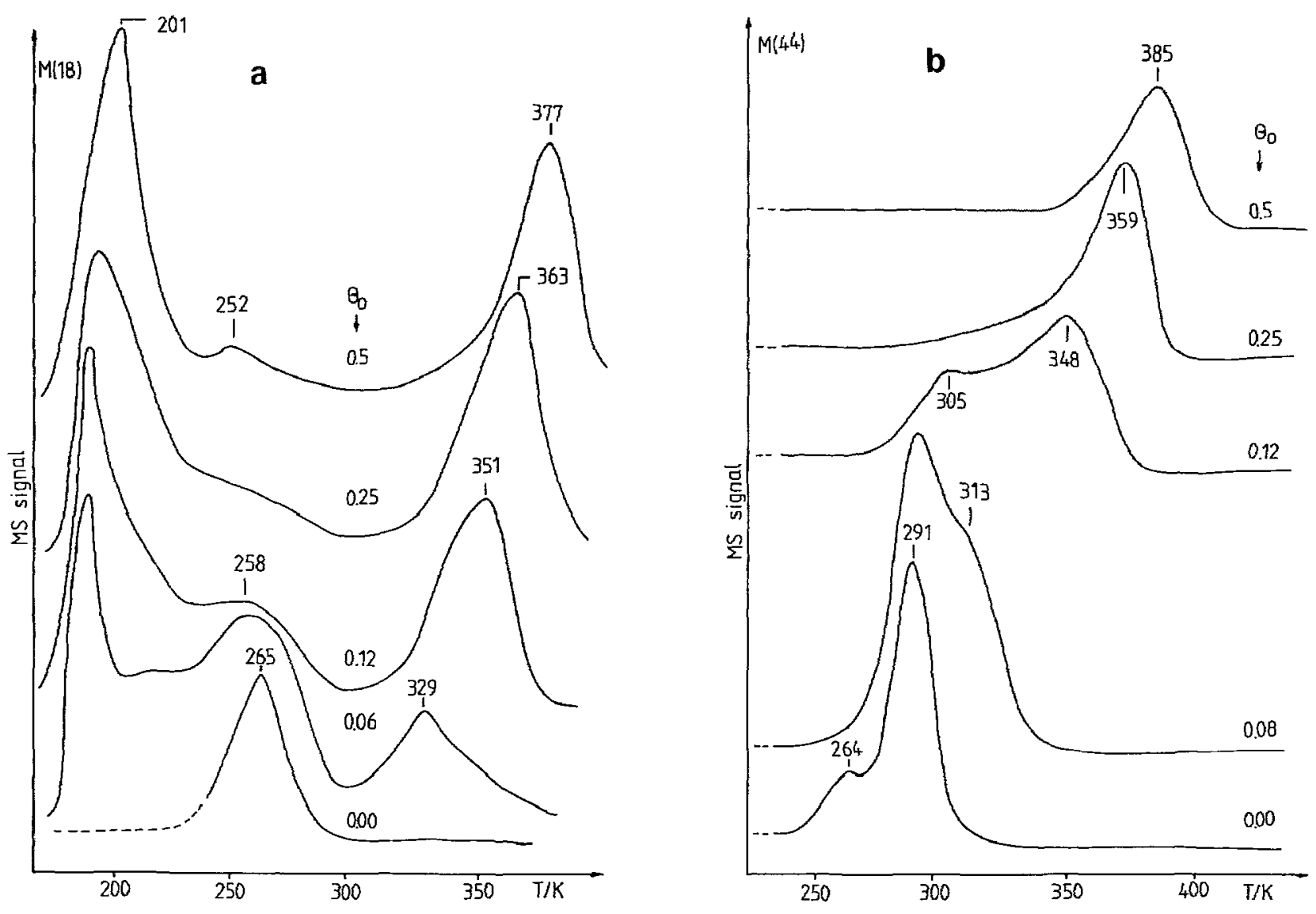

นn

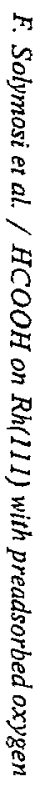

Fig. 7. Effect of oxygen coverage on the thermal desorption of $\mathrm{H}_{2} \mathrm{O}$ (a) and $\mathrm{CO}_{2}$ (b) following $\mathrm{HCOOH}$ adsorption on oxygen-dosed Rh(111) at $100 \mathrm{~K}$ 


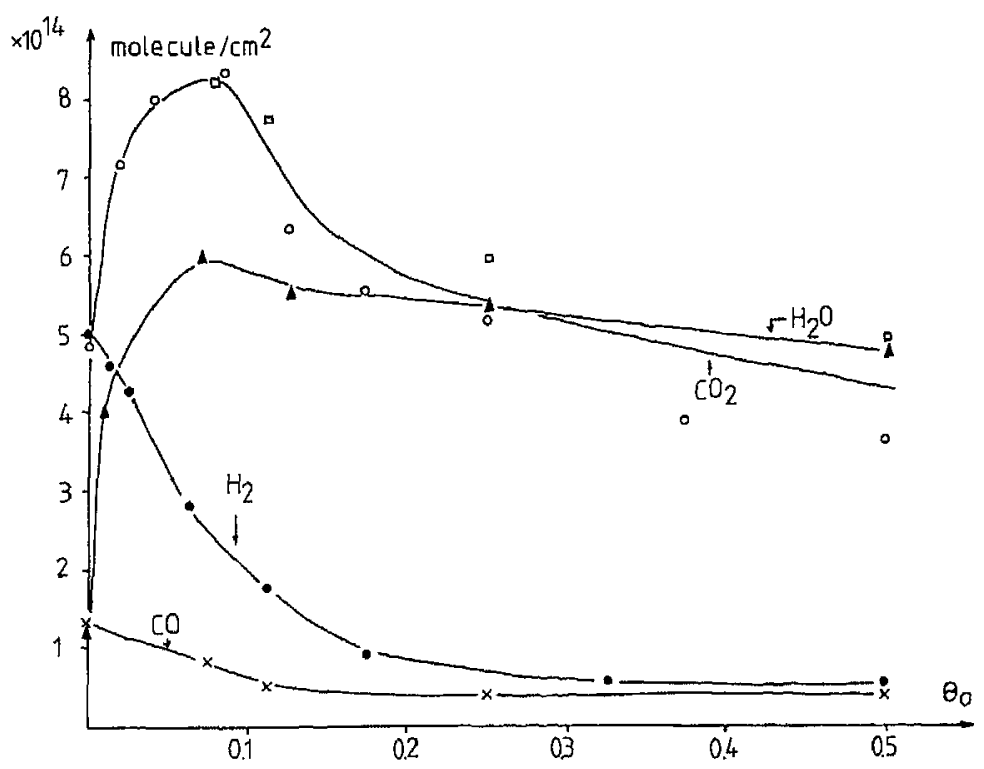

Fig. 8. Formation of $\mathrm{H}_{2}, \mathrm{CO}, \mathrm{H}_{2} \mathrm{O}$ and $\mathrm{CO}_{2}$ as a function of oxygen coverage on Rh(111) following $\mathrm{HCOOH}$ adsorption $\left(6 \mathrm{~L}\right.$ ) at $100 \mathrm{~K}$. Symbols, $\square$ and $\mathrm{O}$, for $\mathrm{CO}_{2}$ correspond to different series of experiments. The preadsorbed oxygen has been completely reacted up to about $\theta_{0} \approx 0.2$. At $\theta_{\mathrm{O}}=0.5$ approximately half of the preadsorbed oxygen remained on the surface.

same time, the desorption characteristic of clean $\mathrm{Rh}$ in the low-temperature range ceased. The amount of $\mathrm{CO}_{2}$ produced increased up to $\theta_{\mathrm{O}}=0.08$, and then decreased. A similar feature was observed for the evolution of $\mathrm{H}_{2} \mathrm{O}$. The desorption at $T_{\mathrm{p}}=265 \mathrm{~K}$ gradually decreased and at $\theta_{\mathrm{O}}=0.06$ new desorption peaks appeared at 184 and $329 \mathrm{~K}$. These peaks became larger at higher oxygen coverage and the latter was characterized by higher $T_{\mathrm{p}}$ values. The amount of $\mathrm{H}_{2}$ gradually decreased as the surface concentration of adsorbed oxygen increased; this was accompanied by an increase in $T_{\mathrm{p}}$. Above $\theta_{\mathrm{O}}=0.3$, only a very small amount of $\mathrm{H}_{2}$ (one-tenth of that determined for a clean surface) was evolved. A similar decrease was observed in the amount of $\mathrm{CO}$ (fig. 8).

In fig. 8, the amounts of the products formed are plotted as a function of the oxygen coverage. It shows that the sum of the amounts of $\mathrm{CO}$ and $\mathrm{CO}_{2}$ exhibits a maximum at $\theta_{\mathrm{O}} \approx 0.1$, which indicates that at this coverage the adsorbed oxygen increases the surface concentration of irreversibly adsorbed $\mathrm{HCOOH}$, i.e. the formate species. In order to interpret these results, in a separate study we investigated the effect of preadsorbed oxygen on the desorption of $\mathrm{H}_{2} \mathrm{O}$ and $\mathrm{CO}_{2}$ from $\mathrm{Rh}(111)$. Although we found that the oxygen adatoms increase the values of $T_{\mathrm{p}}$ for both compounds, the desorption of $\mathrm{H}_{2} \mathrm{O}$ and $\mathrm{CO}_{2}$ occurred still at significantly lower temperatures than 
following $\mathrm{HCOOH}$ adsorption on an oxygen dosed $\mathrm{Rh}(111)$ surface. This suggests that the higher temperatures for the evolution of $\mathrm{H}_{2} \mathrm{O}$ and $\mathrm{CO}_{2}$ in the latter case is due to the stabilization of formate species on the surface.

\subsubsection{UPS studies}

Fig. 9 shows the photoemission spectra of adsorbed HCOOH on oxygen covered surfaces. The preadsorbed oxygen caused a strong peak at 5.7-6.0 eV. The adsorption of $\mathrm{HCOOH}$ at $100 \mathrm{~K}$ produced the same feature as on a clean surface, but all peaks were somewhat shifted to lower binding energies $(6,8.1$, 9.1, 10.9, $15.1 \mathrm{eV}$ ). The intensities of the peaks (at same $\mathrm{HCOOH}$ exposures) remained unaltered. Upon heating the adsorbed layer to higher temperature, the intensity of all photoemission peaks decreased. At $185 \mathrm{~K}$ a new "four-

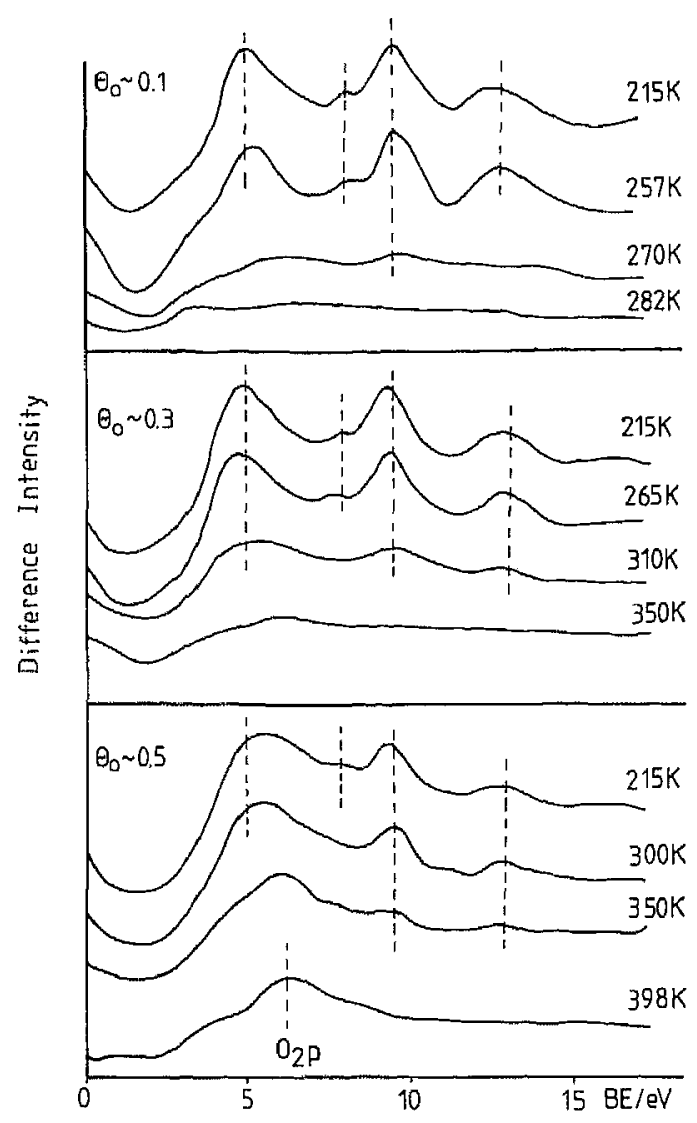

Fig. 9. He II photoelectron spectra of adsorbed HCOOH on $\mathrm{Rh}(111)$ at different oxygen coverages. $\mathrm{HCOOH}(2.4 \mathrm{~L}$ ) was adsorbed at $100 \mathrm{~K}$ and then the sample was heated up first to 215 $\mathrm{K}$ to desorb the condensed $\mathrm{HCOOH}$, and then to different temperatures. 
peaked structure" developed, similarly to the oxygen-free surface, which was attributed to the formation of formate species. A typical feature of this spectrum is the appearance of a peak at $13.1 \mathrm{eV}$. Further raising the temperature of the sample caused an intensification of the peaks up to $215-265 \mathrm{~K}$. As concerns the effect of oxygen coverage on the intensities of the peaks the optimum oxygen coverage was found to be $\theta_{\mathrm{o}}=0.1-0.3$.

Important observations are: (i) the photoemission signals on oxygen-dosed surfaces exhibited markedly higher stability than on a clean $R h$ and (ii) there are no other signals in the spectra due to the products of surface reactions (fig. 9). The highest temperature where the peaks were detectable showed the following variation with the oxygen coverage: $249 \mathrm{~K}$ at $\theta_{\mathrm{O}}=0.0,270 \mathrm{~K}$ at $\theta_{\mathrm{O}}=0.1,310 \mathrm{~K}$ at $\theta_{\mathrm{O}}=0.3$ and $350 \mathrm{~K}$ at $\theta_{\mathrm{O}}=0.5$.

\section{Discussion}

\subsection{Clean surface}

\subsubsection{Adsorption and reactions of $\mathrm{HCOOH}$}

$\mathrm{HCOOH}$ adsorbs readily on a clean $\mathrm{Rh}(111)$ surface at $100 \mathrm{~K}$ with a high sticking probability, which decreases only slightly up to monolayer coverage. The high sticking probability, which may mean an effective energy accommodation, is characteristic of the adsorption of organic molecules which do not decompose at the adsorption temperature. The adsorption occurs in a random fashion, as LEED measurements did not reveal any long-range order after the removal of weakly adsorbed $\mathrm{HCOOH}$ from the surface.

The adsorption of $\mathrm{HCOOH}$ at $100 \mathrm{~K}$ produced two adsorption states. The more strongly bonded one $(\beta)$ desorbed at $202 \mathrm{~K}$ with an activation energy of $48 \mathrm{~kJ} / \mathrm{mol}$. This state was saturated at $6 \mathrm{~L}$, giving rise to an apparent surface concentration of $5.5 \times 10^{13} \mathrm{HCOOH}$ molecules $/ \mathrm{cm}^{2}$. The formation of this state caused a decrease in $\Delta \phi$. From this change it can be concluded that the species formed has a positive outward dipole moment. We suppose that the $\mathrm{HCOOH}$ is bonded end-on via the hydroxyl group and that the $\mathrm{O}-\mathrm{H}$ bond is strongly perturbated by bonding to the surface. The weakly bonded $\mathrm{HCOOH}$ $(\alpha)$ started to develop practically immediately after the formation of the chemisorbed layer, without saturation. The desorption energy of this state is $42 \mathrm{~kJ} / \mathrm{mol}$. On the basis of the characteristics of the desorption of $\mathrm{HCOOH}$ in the two states, the $\beta$-peak is attributed to a monolayer, while the $\alpha$-peak is ascribed to multilayers. The desorption temperature of the latter was quite similar to that of formic acid multilayers on other metals [22-25].

The fact that several other products desorbed at higher temperatures indicates that, in addition to these adsorption states, a third irreversibly adsorbed $\mathrm{HCOOH}$ species, very probably in the form of formate, also exists on the $R h(111)$ surface. 
The surface concentration of irreversibly adsorbed formate (calculated from the amounts of the decomposition products $\mathrm{CO}$ and $\mathrm{CO}_{2}$ ) is $6.3 \times 10^{14} \mathrm{HCOO}$ molecules $/ \mathrm{cm}^{2}$, while the total amount of chemisorbed $\mathrm{HCOOH}$ is $6.9 \times 10^{14}$ $\mathrm{HCOOH}$ molecules $/ \mathrm{cm}^{2}$. Taking into account the surface concentration of $\mathrm{Rh}$ atoms on the (111) face $\left(1.59 \times 10^{15}\right.$ atoms $\left./ \mathrm{cm}^{2}\right)$, we find that the chemisorbed $\mathrm{HCOOH}$ occupies almost $50 \%$ of the surface $\mathrm{Rh}$ atoms, i.e. $\theta_{\mathrm{HCOOH}} \approx$ 0.5 .

As $\mathrm{CO}_{2}$ bonds weakly to a clean $\mathrm{Rh}(111)$ surface (the desorption of $\mathrm{CO}_{2}$ following its adsorption at $100 \mathrm{~K}$ on $\mathrm{Rh}(111)$ is complete at $270 \mathrm{~K}$ at this coverage [26]), the evolution of $\mathrm{CO}_{2}$ is indicative of the decomposition of the formate species on $\mathrm{Rh}(111)$. The data presented in fig. 2 suggest that the decomposition of formate starts at around $200 \mathrm{~K}$ :

$\mathrm{HCOO}_{(\mathrm{a})} \rightarrow \mathrm{CO}_{2}+\mathrm{H}_{(\mathrm{a})}$.

While reaction ( 1 ), the cleavage of $\mathrm{C}-\mathrm{H}$ bond, is the dominant mode of decomposition of the formate species, the evolution of small amounts of $\mathrm{H}_{2} \mathrm{O}$ and $\mathrm{CO}$ suggests the occurrence of the rupture of $\mathrm{C}-\mathrm{O}$ bond, too:

$\mathrm{HCOO}_{(\mathrm{a})} \rightarrow \mathrm{H}_{(\mathrm{a})}+\mathrm{CO}_{(\mathrm{a})}+\mathrm{O}_{(\mathrm{a})}$,

followed by water formation in secondary reactions.

We may speculate that the structures and the bonding modes of formates decomposing according to reactions (1) and (2) are different. For convenience the first type will be denoted by $\mathrm{A}$ and the second type by $\mathrm{B}$.

The desorption of $\mathrm{H}_{2} \mathrm{O}(\beta)$ from a clean $\mathrm{Rh}(111)$ surface occurs above 170 $\mathrm{K}$ with $T_{\mathrm{p}}=182 \mathrm{~K}$ [27], while in the present case $T_{\mathrm{p}}$ for $\mathrm{H}_{2} \mathrm{O}$ evolution was $252-268 \mathrm{~K}$, which is a significantly higher temperature. This feature suggests that the evolution of $\mathrm{H}_{2} \mathrm{O}$ is a reaction-limited step. As the peak temperatures for the formation of $\mathrm{CO}$ agrees well with those obtained after the adsorption of $\mathrm{CO}$ on this surface, we conclude that the formation of $\mathrm{CO}$ is a desorptionlimited process. The facts that both $\mathrm{H}_{2} \mathrm{O}$ and $\mathrm{CO}$ formed attain their highest concentrations at low $\mathrm{HCOOH}$ exposure, and that the ratio $\mathrm{CO}_{2} / \mathrm{CO}$ increases from -0.5 to -4 as the coverage increases indicate that the form $B$ predominates at very low coverage, but its formation soon ceases.

Alternatively, we may assume that there are certain active sites on the $\mathrm{Rh}$ surface which form strong bonds with the oxygen of formate and promote the cleavage of the $\mathrm{C}-\mathrm{O}$ bond. EELS measurements are planned to determine the types of formate on $\mathrm{Rh}$ surface and their stability region.

We may speculate as to whether the production of $\mathrm{CO}$ is the result of secondary reactions, namely the dissociation of $\mathrm{CO}_{2}$. Our recent studies on the adsorption and dissociation of $\mathrm{CO}_{2}$ over $\mathrm{Rh}$ clearly showed [26] that $\mathrm{CO}_{2}$ did not dissociate on a carefully cleaned $\mathrm{Rh}(111)$ surface (which was actually the same sample as used in the present work). However, the dissociation of $\mathrm{CO}_{2}$ did occur if the $\mathrm{Rh}$ surface contained boron impurity segregated from the bulk 
[26]. It is very likely that the much larger amount of $\mathrm{CO}$ formed on $\mathrm{Rh}$ foil in the surface decomposition of $\mathrm{HCOOH}$ is mostly due to the effect of this boron impurity [16]. This view is supported by the EELS spectra, where an intense loss feature was produced at $9.5 \mathrm{eV}$ during heating of the $\mathrm{HCOOH}$-covered $\mathrm{Rh}$ foil to above $300 \mathrm{~K}$ [15].

We now have strong evidence that the $9.5 \mathrm{eV}$ loss is due to some kind of boron oxide formed in a reaction between surface boron and oxygen-containing adsorbed species [27]. This loss was never produced under similar conditions on a clean $\mathrm{Rh}$ surface $[20,26,27]$, and it was not detected in the present case either. We have to take also into account that the adsorbed hydrogen can promote the dissociation of $\mathrm{CO}_{2}$ on $\mathrm{Rh}$. This was observed both for supported $\mathrm{Rh}$ [5-10] and for $\mathrm{Rh}(111)$ single crystal [26]. However the extent of $\mathrm{CO}_{2}$ dissociation on Rh(111), even under favorable condition, was much smaller than inferred from the amount of $\mathrm{CO}$ formed in the present case.

\subsubsection{Spectroscopic features of adsorbed $\mathrm{HCOOH}$}

The adsorption of $\mathrm{HCOOH}$ has been studied by photoelectron spectroscopy on $\mathrm{Au}[28], \mathrm{Ni}[28]$ and $\mathrm{Cu}[28,22]$ surfaces, but no UPS studies have so far been performed on the adsorption of $\mathrm{HCOOH}$ on $\mathrm{Pt}$ metals. The low-temperature photoelectron spectrum of $\mathrm{HCOOH}$ adsorbed on $\mathrm{Rh}(111)$ displays good agreement with that described previously [28]. Photoemission peaks appeared at $6.4,8.5,10.5,11.9$ and $16.2 \mathrm{eV}$, which are attributed to the $10 \mathrm{a}, 2 \mathrm{~b}$, the $9 \mathrm{a}$, the $1 \mathrm{~b}$, the $8 \mathrm{a}, 7 \mathrm{~b}$ and the $6 \mathrm{a}$ orbitals, respectively, of molecularly adsorbed $\mathrm{HCOOH}$. The observed spectra are consistent with the results of gas-phase photoemission studies [28]. The difference between the spectra of the gas and condensed phases is that the two peaks due to the $10 \mathrm{a}$ and $2 \mathrm{~b}$ orbitals (well separated in the gas phase at binding energies of 11.5 and $12.8 \mathrm{eV}$ below the vacuum level) are not resolved in the spectrum of the condensed phase, but appear as a single broad peak at around $6.2 \mathrm{eV}$. This can be explained by the formation of $\mathrm{HCOOH}$ dimers [28]. Similarly as for $\mathrm{Cu}$ and Ni surfaces [28], the hydrogen-bonding in the dimer perturbs only the outer, $10 \mathrm{a}$ and $2 \mathrm{~b}$ orbitals of the monomer.

The dissociation of $\mathrm{HCOOH}$, i.e. the formation of formate, was assumed to occur on all the above metals. This was supported by well-detectable spectral changes characterized by a new four-peak structure, at 3.7-4.9, 8.1, 9.6 and $13.2 \mathrm{eV}$ attributed to the $1 a_{2}, 6 a_{1}, 4 b_{2}$, the $1 b_{1}$, the $3 b_{2}, 5 a_{1}$, and the $4 a_{1}$ orbitals $[22,28,29,30]$. The UPS spectrum of adsorbed formate is in agreement with the SCF-MO molecular orbital calculations for this anion [31]. On clean $\mathrm{Rh}(111)$, these spectral features were clearly detected at $151 \mathrm{~K}$. When our UPS spectrum is compared with those obtained for other metals or deduced from theoretical calculations, it appears that the highest-lying orbitals $\left(1 \mathrm{a}_{2}, 6 \mathrm{a}_{1}\right.$, $4 b_{2}$ ) show a little perturbation due to bonding with the $\mathrm{Rh}$ surface. Somewhat smaller perturbations occurred in the cases of $\mathrm{Ni} \mathrm{[28],} \mathrm{Cu}$ [28] and $\mathrm{Ag}$ [29]. 
When the $\mathrm{Rh}(111)$ surface covered by formate was annealed at above 240 $\mathrm{K}$, the peaks attributed to the formate diminished, while two new peaks were detected at 8.2 and $11.2 \mathrm{eV}$. We attribute these peaks to the $5 \sigma / 1 \pi$ and $4 \sigma$ molecular orbitals, respectively, of adsorbed $\mathrm{CO}[32,33]$. These peaks were eliminated only at around $522 \mathrm{~K}$, which corresponds to the desorption temperature for $\mathrm{CO}$.

There was no sign of the presence of other adsorbed species, such as $\mathrm{CO}_{2}$, which is the main product of surface decomposition. This is in accord with our finding [26] that $\mathrm{CO}_{2}$ is weakly bonded to $\mathrm{Rh}$, and desorbs at once in the temperature range $200-250 \mathrm{~K}$ of formate decomposition.

The EEL spectrum of adsorbed $\mathrm{HCOOH}$ at $100 \mathrm{~K}$ agreed well with those observed for $\mathrm{Rh}$ foil [15]. The origin of these losses has been discussed earlier in detail [15], but no comparison with UPS was made. Taking into account the energy levels of adsorbed $\mathrm{HCOOH}$ on the $\mathrm{Rh}(111)$ surface determined by UPS we assign the observed losses at $7.9,11.3$ and $14.8 \mathrm{eV}$ to the intramolecular electron transitions from the $10 a, 2 b$, the $9 a, 1 b$, and the $8 a, 7 a$ orbitals to the unfilled $3 b$ or $11 \mathrm{a}$ orbitals of $\mathrm{HCOOH}$, respectively, which are situated at around $1.6-2.0 \mathrm{eV}$ above the Fermi level. When the HCOOH covered $\mathrm{Rh}(111)$ was heated above $228 \mathrm{~K}$, or $\mathrm{HCOOH}$ was adsorbed at $300 \mathrm{~K}$, a new loss feature developed at $13.1 \mathrm{eV}$ which - no doubt - belongs to the adsorbed $\mathrm{CO}$ formed in the surface reaction $[15,20,26]$. The stability regions of the losses due to chemisorbed $\mathrm{HCOOH}$ and $\mathrm{CO}$ are in accord with those deduced from TDS and UPS studies.

\subsection{Oxygen-dosed surfaces}

The effects of preadsorbed oxygen on the adsorption of different molecules have been investigated in great detail and well documented by Roberts and coworkers [34,35], Madix and coworkers [24,36,37] and Solymosi and coworkers [38-43].

Preadsorbed oxygen exerted a readily observable influence on the interaction of $\mathrm{HCOOH}$ with the $\mathrm{Rh}(111)$ surface:

(i) it increased the extent of dissociation of formic acid and hence the surface concentration of the formate species by a factor of 1.3 (fig. 8), and

(ii) it extended the region of stability of the surface formate by at least $80-100$ $\mathrm{K}$ as exhibited by TDS and UPS studies (figs. 7 and 9).

The desorption of condensed and molecularly bonded $\mathrm{HCOOH}$ was only slightly altered by oxygen adatoms.

Qualitatively similar features were found in our laboratory for the adsorption of $\mathrm{HNCO}$ [38] and $\mathrm{CH}_{3} \mathrm{OH}$ [39] on an oxygen-dosed $\mathrm{Rh}(111)$ surface. The promoting effect of preadsorbed oxygen in the dissociation of $\mathrm{HCOOH}$ can be attributed to the reaction

$$
\mathrm{O}_{(\mathrm{a})}+\mathrm{HCOOH}_{(\mathrm{g})} \rightarrow \mathrm{OH}_{(\mathrm{a})}+\mathrm{HCOO}_{(\mathrm{a})} \text {, }
$$


i.e. to the formation of a strong $\mathrm{O}-\mathrm{H}$ bond. In other words the oxygen adatom reacts as a Brönsted base toward $\mathrm{HCOOH}$, by abstracting the acidic hydrogen from $\mathrm{HCOOH}$ [24]. The resulting adsorbed $\mathrm{OH}$ groups interact and $\mathrm{H}_{2} \mathrm{O}$ is desorbed:

$\mathrm{OH}_{(\mathrm{a})}+\mathrm{OH}_{(\mathrm{a})} \rightarrow \mathrm{O}_{(\mathrm{a})}+\mathrm{H}_{2} \mathrm{O}_{(\mathrm{g})}$,

with $T_{p}=215 \mathrm{~K}$ [44]. Although careful analysis of the TD curves for $\mathrm{H}_{2} \mathrm{O}$ reveals desorption at this temperature, a larger amount of $\mathrm{H}_{2} \mathrm{O}$ is desorbed at $184-200 \mathrm{~K}$. This suggests that, in addition to steps 3 and 4, it is also necessary to consider the occurrence of the reaction

$\mathrm{OH}_{(\mathrm{a})}+\mathrm{HCOOH} \rightarrow \mathrm{HCOO}_{(\mathrm{a})}+\mathrm{H}_{2} \mathrm{O}_{(\mathrm{g})}$.

An interesting feature of the effect of preadsorbed oxygen is the significant stabilization of formate on $\mathrm{Rh}$. The fact that the proton reacts with adsorbed oxygen (and is desorbed in the form of $\mathrm{H}_{2} \mathrm{O}$ ) can certainly contribute to the increases in the lifetime and stability of adsorbed formate, as it lowers the probability of the reverse reaction, i.e. the associative desorption of the molecule. Another factor which should be taken into account is the blocking of the Rh sites required for the decomposition of the formate species and for the binding of $\mathrm{CO}$ and $\mathrm{H}$. This could be important when the binding of the decomposition products requires a larger number of surface sites than the number occupied by the adsorbed molecule before decomposition, and when the products form strong bonds with the metals (e.g. in $\mathrm{NCO}$ and $\mathrm{CH}_{3} \mathrm{O}$ decompositions), but this is less significant in the present case.

For the $\mathrm{NCO}+\mathrm{O} / \mathrm{Rh}(111)$ system we proposed that the stabilizing effect of preadsorbed oxygen occurs through a ligand effect, which results in a more ionic bond, and thereby in a higher stability [38]. A shift in the $\nu_{\mathrm{as}}(\mathrm{NCO})$ loss towards higher frequency $[38,40]$ strongly supported this view. We believe that this ligand effect plays an important role in the enhanced stability of the formate species on oxygen-dosed Rh surfaces, too.

An alternative mode of stabilization of the formate species would be a structural rearrangement, i.e. an oxygen-induced transformation of the formate into a more stable form.

In the presence of adsorbed oxygen we experienced a significant change in the product distribution; the amounts of $\mathrm{CO}_{2}$ and particularly $\mathrm{H}_{2} \mathrm{O}$ increased greatly at the expense of $\mathrm{H}_{2}$ and $\mathrm{CO}$, indicating that an oxidation process too occurred on the surface:

$\mathrm{CO}_{(\mathrm{a})}+\mathrm{O}_{(\mathrm{a})} \rightarrow \mathrm{CO}_{2(\mathrm{~g})}$

and/or

$2 \mathrm{HCOO}_{(\mathrm{a})}+\mathrm{O}_{(\mathrm{a})} \rightarrow 2 \mathrm{CO}_{2}+\mathrm{H}_{2} \mathrm{O}$. 
One could also consider a variation in the selectivity of formate decomposition as a function of oxygen coverage. The fact that the values of $T_{p}$ for the new peaks of $\mathrm{CO}_{2}$ and $\mathrm{H}_{2} \mathrm{O}$ (caused by preadsorbed oxygen) are practically identical at the same oxygen coverages $\left(T_{\mathrm{p}}=329-377 \mathrm{~K}\right)$ strongly supports the idea that they are formed in the same surface reaction, very likely in the direct oxidation of formate species. This reaction was also assumed to occur on an Au(110) surface [24].

\section{Catalytic implications}

As outlined in the introduction, formate is considered to be an important surface intermediate in several catalytic reactions on $\mathrm{Rh}$ catalyst. The results of the present study demonstrate that formate is an unstable species on a clean $\mathrm{Rh}$ surface: it decomposes completely at around $300 \mathrm{~K}$. However, chemisorbed oxygen greatly enhances the stability of formate on $\mathrm{Rh}$. Hence, it seems quite possible that, due to this stabilizing effect, the formate species has a sufficient lifetime on supported $\mathrm{Rh}$, even at higher temperature, to function as a surface intermediate in the catalytic synthesis of oxygenated compounds in the hydrogenation of carbon oxides.

\section{References}

[1] D.C. Grenoble, M.M. Estadt and D.F. Ollis, J. Catalysis 67 (1981) 90.

[2] A. Kienemann, J.P. Hindermann, R. Brault and H. Idriss, Am. Chem. Soc. Div. Petrol. Chem. 31 (1986) 46.

[3] F. Solymosi, I. Tombácz and M. Kocsis, J. Catalysis 75 (1982) 78.

[4] M. Ichikawa and K. Shikakura, in: Proc. 7th Intern. Congr. on Catalysis, Tokyo, 1980, Part B, p. 925.

[5] F. Solymosi, A. Erdöhelyi and T. Bánsági, J. Catalysis 68 (1981) 371.

[6] M.A. Henderson and S.D. Woorley, J. Phys. Chem. 89 (1985) 1417.

[7] T. Tizuka, Y. Tanaka and K. Tanabe, J. Mol. Catalysis 17 (1982) 381.

[8] F. Solymosi, A. Erdöhelyi and T. Bánsági, J. Chem. Soc. Faraday Trans. I, 77 (1981) 2645.

[9] F. Solymosi, A. Erdöhelyi and M. Kocsis, J. Catalysis 65 (1980) 428.

[10] Y. Tanaka, T. lizuka and K. Tanabe, J. Chem. Soc. Faraday Trans. I, 78 (1982) 2215.

[11] F. Solymosi, T. Bánsági and A. Erdöhelyi, J. Catalysis 72 (1981) 166.

[12] A. Deluzarche, J.P. Hindermann, R. Kieffer, J. Cressely, R. Stupler and A. Kienemann, Spectra 2000, 75 (1982) 27.

[13] A. Deluzarche, J.P. Hindermann, A. Kienemann and R. Kieffer, J. Mol. Catalysis 31 (1985) 295.

[14] A. Deluzarche, J.P. Hindermann, R. Kieffer and A. Kienemann, Rev. Chem. Intermed. 6 (1985) 625.

[15] F. Solymosi and J. Kiss, J. Catalysis 81 (1983) 95.

[16] F. Solymosi, J. Kiss and I. Kovács, J. Phys. Chem., in press.

[17] S. Anderson and U. Jostell, Surface Sci. 46 (1974) 625.

[18] K. Christmann and J.E. Demuth, J. Chem. Phys. 76 (1982) 6318. 
[19] J. Kiss and F. Solymosi, Surface Sci. 135 (1983) 243.

[20] F. Solymosi, A. Berkó and T.I. Tarnóczi, Surface Sci. 141 (1984) 533.

[21] P.A. Thiel, J.T. Yates, Jr. and W.H. Weinberg, Surface Sci. 82 (1979) 72.

[22] M. Bowker and R.J. Madix, Surface Sci. 102 (1981) 542.

[23] B.A. Sexton and R.J. Madix, Surface Sci. 105 (1981) 177

[24] D.A. Outka and R.J. Madix, Surface Sci. 179 (1987) 361.

[25] N.R. Avery, Appl. Surface Sci. 11/12 (1982) 774.

[26] F. Solymosi and J. Kiss, Surface Sci. 149 (1985) 17.

[27] J. Kiss and F. Solymosi, Surface Sci. 177 (1986) 191.

[28] R.W. Joyner and M.W. Roberts, Proc. Roy. Soc. (London) A350 (1976) 107.

[29] M.A. Barteau and R.J. Madix, Surface Sci. 120 (1982) 262.

[30] B.A. Sexton, A.E. Hughes and N.R. Avery, Surface Sci. 155 (1985) 366.

[31] S.D. Peyerimhoff, J. Chem. Phys. 47 (1967) 349.

[32] C.L. Allyn, T. Gustafsson and W.W. Plummer, Chem. Phys. Letters 47 (1977) 127.

[33] D.E. Peebles, H.C. Peebles and J.W. White, Surface Sci. 136 (1984) 463.

[34] M.W. Roberts, Advan. Catalysis 29 (1980) 55.

[35] S.A. Isa, R.W. Joyner, M.H. Matloob and M.W. Roberts, Appl. Surface Sci. 5 (1980) 345.

[36] R.J. Madix, Advan. Catalysis 29 (1980) 1.

[37] M.A. Barteau, M. Bowker and R.J. Madix, Surface Sci. 94 (1980) 303.

[38] F. Solymosi, A. Berkó and T.I. Tarnóczi, Appl. Surface Sci. 18 (1984) 233.

[39] F. Solymosi, T.I. Tarnóczi and A. Berkó, J, Phys. Chem. 88 (1984) 6170.

[40] M. Surman, S.R. Bare, P. Hofmann, F. Solymosi and D.A. King, to be published.

[41] F. Solymosi and J. Kiss, Surface Sci. 104 (1981) 181.

[42] F. Solymosi and A. Berko, Surface Sci. 122 (1982) 275.

[43] F. Solymosi and L. Bugyi, Surface Sci. 147 (1984) 685.

[44] J.J. Zinck and W.H. Weinberg, J. Vacuum Sci. Technol. 17 (1980) 188. 